Article

\title{
Spectral Reflectance Characteristics and Chlorophyll Content Estimation Model of Quercus aquifolioides Leaves at Different Altitudes in Sejila Mountain
}

\author{
Jiyou Zhu ${ }^{1}$, Weijun $\mathrm{He}^{2}$, Jiangming Yao ${ }^{3}$, Qiang Yu ${ }^{1, *}$ (D), Chengyang $\mathrm{Xu}^{1, *}$, Huaguo Huang ${ }^{1}$ (D) \\ and Catherine Mhae B. Jandug ${ }^{1}$ \\ 1 Key Laboratory for Silviculture and Forest Ecosystem of State Forestry Administration, Key Laboratory for \\ Silviculture and Conservation of Ministry of Education, Research Center for Urban Forestry of Beijing \\ Forestry University, Beijing 100083, China; joezhu1205@gmail.com (J.Z.); huaguo_huang@bjfu.edu.cn (H.H.); \\ cbjandug@gmail.com (C.M.B.J.) \\ 2 Chinese Academy of Forestry, Research Institude of Tropical Forestry, Guangzhou 510520, China; \\ wjhecaf@gmail.com \\ 3 Forestry College of Guangxi University, Nanning 530005, China; jiangming618@gmail.com \\ * $\quad$ Correspondence: yuqiang@bjfu.edu.cn (Q.Y.); cyxu@bjfu.edu.cn (C.X.); Tel.: +86-010-6233-7082 (C.X.)
}

Received: 4 May 2020; Accepted: 20 May 2020; Published: 24 May 2020

\begin{abstract}
Quercus aquifolioides is one of the most representative broad-leaved plants in Qinghai-Tibet Plateau with important ecological status. So far, understanding how to quickly estimate the chlorophyll content of plants in plateau areas is still an urgent problem. Field Spec 3 spectrometer was used to measure hyperspectral reflectance data of Quercus aquifolioides leaves at different altitudes, and CCI (chlorophyll relative content) of corresponding leaves was measured by a chlorophyll meter. The correlation and univariate linear fitting analysis techniques were used to establish their relationship models. The results showed that: (1) Chlorophyll relative content of Quercus aquifolioides, under different altitude gradients, were significantly different. From $2905 \mathrm{~m}$ to $3500 \mathrm{~m}$, chlorophyll relative content increased first and then decreased. Altitude $3300 \mathrm{~m}$ was the most suitable growth area. (2) In 350 550 nm, the spectral reflectance was $3500 \mathrm{~m}>3300 \mathrm{~m}>2905 \mathrm{~m}$. In 750 1100 nm, the spectral reflectivity was $2905 \mathrm{~m}>3500 \mathrm{~m}>3300 \mathrm{~m}$. (3) There were 4 main reflection peaks and 5 main absorption valleys in the leaf surface spectral reflection curve. While, 750 1400 nm was the sensitive range of leaf spectral response of Quercus aquifolioides. (4) The red edge position and red valley position moved to short wave direction with the increase of altitude, while the yellow edge position and green peak position moved to long wave direction first and then to short wave direction. (5) The correlation curve between the original spectrum and the CCI value was the best between the wavelengths $509 \sim 650 \mathrm{~nm}$. The correlation between the first derivative spectrum and CCI value was the best and most stable at 450 500 nm. The green peak reflectance was most sensitive to the relative chlorophyll content of Quercus aquifolioides. The estimation model $R^{2}$ of green peak reflectance was the highest $\left(\mathrm{y}=206.98 \mathrm{e}^{-10.85 \mathrm{x}}, R^{2}=0.8523\right)$, and the prediction accuracy was $95.85 \%$. The research results can provide some technical and theoretical support for the protection of natural Quercus aquifolioides forests in Tibet.
\end{abstract}

Keywords: reflection spectrum; chlorophyll content estimation Model; Quercus aquifolioides; altitude

\section{Introduction}

Altitude is one of the most important site factors that affects plant growth and its physiological ecology [1-3]. Many studies have shown that the average temperature and pressure of the ambient atmosphere decrease and the solar radiation increases with the increase in altitude. These factors 
have an important impact on the morphological structure and physiological structure of plants [3-7]. Therefore, in order to ensure their normal growth, plants at different altitudes have gradually formed their own adaptive mechanism to resist adversity [7-9]. Southeast Tibet is one of the largest primitive forest regions in China, and is the key research area of plateau ecosystem in China. Quercus aquifoliodes is a unique tree species in northwestern Yunnan, southeastern Tibet and western Sichuan, which irreplaceable in water conservation, soil and water conservation and biodiversity protection [10-13]. In particular, after the "two barriers and three belts" (the Qinghai-Tibet plateau ecological barrier, the loess plateau-Sichuan-Yunnan ecological barrier and the northeast forest belt, the northern sand prevention belt and the southern hilly mountain belt form an overall green development ecological contour) as the main body of China's ecological security strategic pattern was put forward, the ecological barrier function and position of Quercus aquifoliodes in Tibet area have become increasingly prominent [14]. At present, the research on this species mainly focuses on litter decomposition characteristics, soil respiration, genetic diversity, population spatial pattern characteristics, etc. [9-13,15]. However, there is still a large gap in the research on spectral characteristics of Quercus aquifoliodes leaves at different altitudes. Therefore, based on the importance and particularity of the region, understanding how to monitor and quickly obtain the growth status of Quercus aquifoliodes in different altitude environments is the key to its ecological service function and value.

In recent years, more researchers have begun to study scientific issues of agriculture and forestry, based on hyperspectral technology, with the rapid development of hyperspectral technology. Research has shown that, compared with conventional research methods, hyperspectral technology has the advantages of simple data acquisition and rich information. Spectral data contain a lot of information, such as chlorophyll content, plant stress, water content, photosynthetic rate, etc. [16-20]. Extracting these information through various methods can effectively solve many ecological problems. Using reflectance spectroscopy to detect the physiological and ecological characteristics of plants has gradually become one of the research hotspots in forestry remote sensing. At present, scholars have carried out a large number of researches and pioneering applications using spectral reflectance, including the correlation between plant pigments and spectral reflectance, physiological adaptation of plants to changes in altitude, adaptation countermeasures of plants to drought conditions and other harsh environments, estimation of green plant productivity, monitoring seasonal changes of plant communities, biodiversity research, detection of plant diseases and insect pests and biological invasion patterns, fire monitoring, monitoring applied to carbon cycle and water cycle, environmental pollution monitoring, etc. [17-28]. However, research on the effects of different altitudes on plants, based on hyperspectral analysis are rarely reported, especially on Quercus aquifoliodes, which are relatively limited. The forest community in Tibet's Sejila Mountain changes obviously with altitude gradient, and the change of plant spectral reflectance with altitude is a problem to be revealed. Quercus aquifoliodes, as an important broad-leaved tree species in Sejila Mountain, has important economic value and ecosystem service value. Therefore, in order to compare the spectral variation characteristics and laws of Quercus aquifoliodes leaves under different altitude gradients, explore how to infer the photosynthetic capacity of Quercus aquifoliodes leaves, under different altitude gradients, based on hyperspectral parameters, and further analyze its sensitive band to altitude, in order to provide theoretical basis for further understanding its growth characteristics and strategies for adapting to the environment.

\section{General Situation and Research Methods of the Research Area}

\subsection{Survey of Research Area}

The study area is located in the Tibetan autonomous region of Tibet's Sejila mountain, between east longitude $94^{\circ} 19^{\prime}-94^{\circ} 53^{\prime}$, north latitude $29^{\circ} 33^{\prime}-30^{\circ} 00^{\prime}$. This region is a typical sub-alpine temperate semi-humid climate zone with distinct dry and wet seasons. The altitude range of the study area is $2900-3500 \mathrm{~m}$, the annual average temperature is about $-0.73^{\circ} \mathrm{C}$, the average temperature in the highest month (July) is $9.23{ }^{\circ} \mathrm{C}$, the average temperature in the lowest month (January) $-13.98{ }^{\circ} \mathrm{C}$, 
the extreme minimum temperature $-31.6^{\circ} \mathrm{C}$, the extreme maximum temperature $24.0{ }^{\circ} \mathrm{C}$, the average annual sunshine hours $1150.6 \mathrm{~h}$, the sunshine percentage $26.1 \%$, and the maximum sunshine hours are December $(151.7 \mathrm{~h}$ ). The sunshine percentage is $40 \%$, the average annual relative humidity is $78.83 \%$, the average annual precipitation is $1134.1 \mathrm{~mm}$, and the evaporation amount is $544.0 \mathrm{~mm}$, accounting for $48.0 \%$ of the average annual precipitation. June-September is the rainy season, accounting for $75 \sim 82 \%$ of the annual rainfall, of which August has the most rainfall, averaging $294.2 \mathrm{~mm}$, accounting for $30 \%$ of the annual rainfall. The soil is mainly mountainous brown soil and acidic brown soil, with a $\mathrm{pH}$ value of 4-6, an average thickness of $60 \mathrm{~cm}$, and no obvious degree of humus. The stand structure of Quercus aquifolioides in Sichuan-Yunnan region is relatively single, mostly distributed in pure forests, sometimes mixed with Pinus densata Mast to become dominant species in secondary forest.

\subsection{Leaf Reflectance Spectrum Collection and Chlorophyll Determination}

We selected 60 functional leaves in the middle of Quercus aquifolioides plants at each altitude gradient. Spectral data were collected using an ASD FieldSpec3 portable near infrared spectrometer (Analytical Spectral Device, Almero, Netherlands). The band range of ASD spectrometer is $300 \sim 2500 \mathrm{~nm}$. The sampling interval is $1.4 \mathrm{~nm}(350 \sim 1000 \mathrm{~nm}$ band) and $2 \mathrm{~nm}(1000 \sim 2500 \mathrm{~nm}$ band) respectively in different band ranges. The spectral reflection curve was set to 10 repetitions, and the final output spectral data was the average value of the 10 data. The operation procedures of the instrument were as follows: optimizing spectrometer $\rightarrow$ dark scanning $\rightarrow$ white board scanning $\rightarrow$ adjusting transmission mode $\rightarrow$ aiming optical fiber at the sample $\rightarrow$ saving the value after reading is stable (Figure 1) [16].
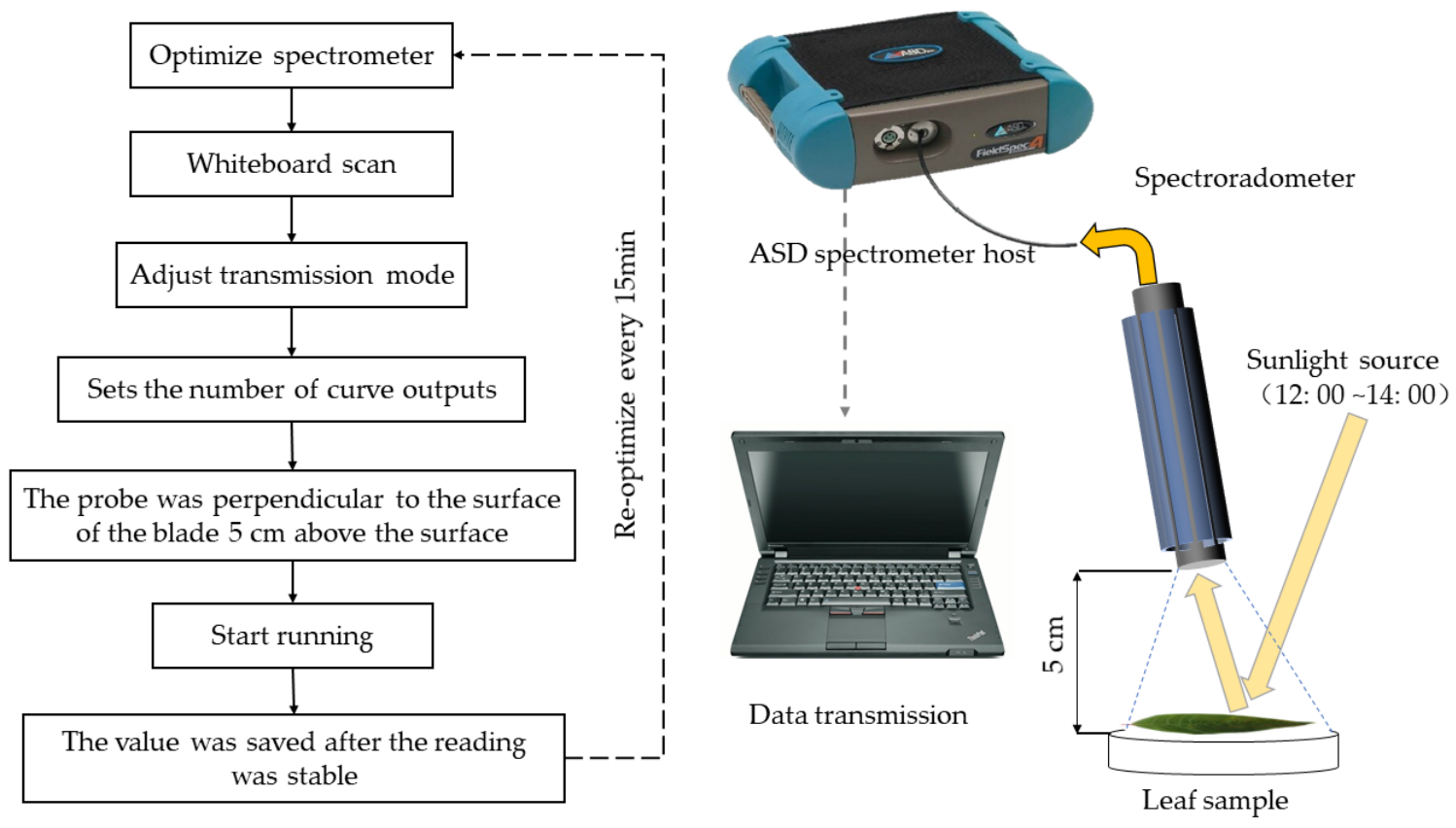

Figure 1. Flow chart of leaf spectrum measurement based on ASD spectrometer [16].

The relative Chlorophyll content index (CCI) was measured by CCM-200 plus chlorophyll meter (OPTI-Science, Tyngsboro, MA, USA), with the resolution of $\pm 0.1 \mathrm{CCI}$ and the measurement range of $0.71 \mathrm{~cm}^{2}$. The principle of this instrument is to measure the relative content of chlorophyll in the measured object by the optical absorptivity when the light source is excited in red light and infrared light [19].

\subsection{Data Processing Method}

Analysis and processing of spectral data were based on ViewSpecPro software, and correlation analysis of spectral parameters and chlorophyll was based on Origin 2019b software and Excel 2019 software. 


\section{Results and Analysis}

\subsection{Chlorophyll Content and Spectral Characteristics of Quercus aquifolioides at Different Altitudes}

Photosynthesis accumulates and stores important energy and substances for plant growth. Chlorophyll, as the basic pigment in plants, plays an important role in the absorption, transmission and transformation of light energy. As can be seen from Figure 2, the relative values of chlorophyll content of Quercus aquifolioides under different altitude gradients were significantly different. From $2905 \mathrm{~m}$ to $3500 \mathrm{~m}$, the relative chlorophyll content of Quercus aquifolioides increased first and then decreased, reaching a peak at $3200 \mathrm{~m}$ and decreasing at $3500 \mathrm{~m}$. This showed that Quercus aquifolioides has lower photosynthetic capacity at $2905 \mathrm{~m}$ compared with $3200 \mathrm{~m}$. At the same time, under high altitude and strong radiation environment, Quercus aquifolioides at $3500 \mathrm{~m}$ reduced its chlorophyll content. This can reduce its absorption of light and weaken the pressure of the light system, thus avoiding its peroxidation. The chlorophyll content, in this study, showed a rising trend first and then falling with the elevation. Similar results have been reported in the study of chlorophyll content in Acer ginnala and the study of the forest structure of Phyllostachys heterocycle [29,30]. The increase of chlorophyll content to a certain extent can accumulate more photosynthetic products for the growth of plants, and the synthesis is affected by light intensity. As the light intensity at low altitude is weaker, and the light intensity at middle altitude increases, it is more conducive to chlorophyll synthesis [30,31]. With the further increase in altitude, environmental factors, such as air humidity reduction, ultraviolet radiation and low temperature at high altitude become more serious. This may, in turn, cause the chlorophyll synthesis to be blocked or the chlorophyll decomposition to be accelerated, causing the chlorophyll content in the leaves to decrease $[32,33]$. Therefore, with the increase in altitude, chlorophyll showed first a rising trend and then falling, which also showed that the middle altitude was more conducive to the photosynthesis and growth of plants.

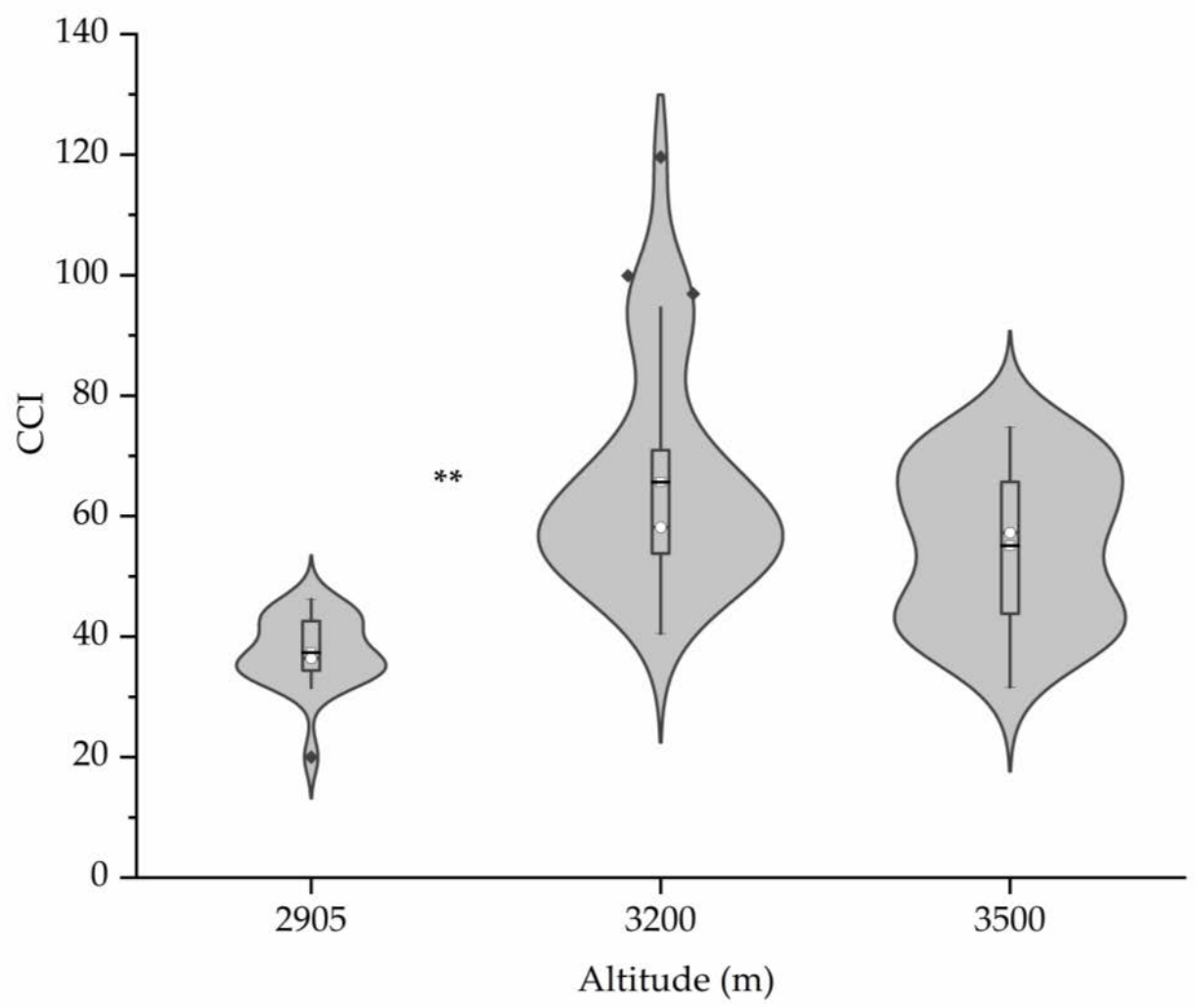

Figure 2. Relative chlorophyll content of Quercus aquifolioides at different altitudes. ${ }^{* *}$ indicates that the parameters are significantly different at $p<0.01$ level. CCI (chlorophyll content index). 


\subsection{Spectral Characteristics of Quercus aquifolioides with Different Altitude Gradient}

As shown in Figure 3, the trend changes of leaf spectral reflectance curves of Quercus aquifolioides were generally consistent under different altitude gradients. In the visible light band range (350 700 nm), there are obvious differences in spectral reflectance. In the range of $350 \sim 700 \mathrm{~nm}$, the reflectivity of each band of $3500 \mathrm{~m}$ is greater than $3300 \mathrm{~m}$ and the reflectivity of $2905 \mathrm{~m}$. As shown in Figure 4, their maximum reflectance ratios were 1.39, and 1.26, respectively. In the range of 350-500 nm, the reflectance of $3300 \mathrm{~m}$ was greater than that of $2905 \mathrm{~m}$, and the maximum ratio of reflectance was 0.95 . In the range of $500 \sim 700 \mathrm{~nm}$, the reflectivity of $2905 \mathrm{~m}$ was greater than that of $3300 \mathrm{~m}$, and the reflectivity ratio was 1.14 at the maximum. In the near infrared band $(750 \sim 1100 \mathrm{~nm})$, the reflectivity of $2905 \mathrm{~m}$ was higher than that of $3500 \mathrm{~m}$ and $3300 \mathrm{~m}$, and their maximum reflectivity ratios were 1.56, and 1.75 , respectively. The closer the reflectance ratio was to 1 , the smaller the difference between them was.

In the range of 350 1800 nm, there were 4 main reflection peaks and 5 main absorption valleys in the leaf surface spectral reflection curve of Quercus aquifolioides, and their positions were basically the same. The reflection peaks were located at $550 \mathrm{~nm}, 1096 \mathrm{~nm}, 1273 \mathrm{~nm}$, and $1656 \mathrm{~nm}$, respectively, and the absorption valleys were located at 350-500 nm, 600-750 nm, 950-1050 nm, 1200 1250 nm, and 1400 1500 nm, respectively.

As shown in Figures 3 and 4, the spectral reflectance of Quercus aquifolioides leaves at different altitudes in the visible light to near infrared band (350-1800 nm) was the most distinguishable in the range of 750-1400 nm, indicating that this band was the sensitive range of spectral response of plants to different altitudes. In addition, we can see that the slope of the spectral reflectance curve of Quercus aquifolioides leaves has a sharp increase trend in the range of $700 \sim 780 \mathrm{~nm}$. Studies have shown that the phenomenon of plants increasing suddenly in this wave band belongs to the typical "red edge effect" characteristic of plants $[16,33,34]$.

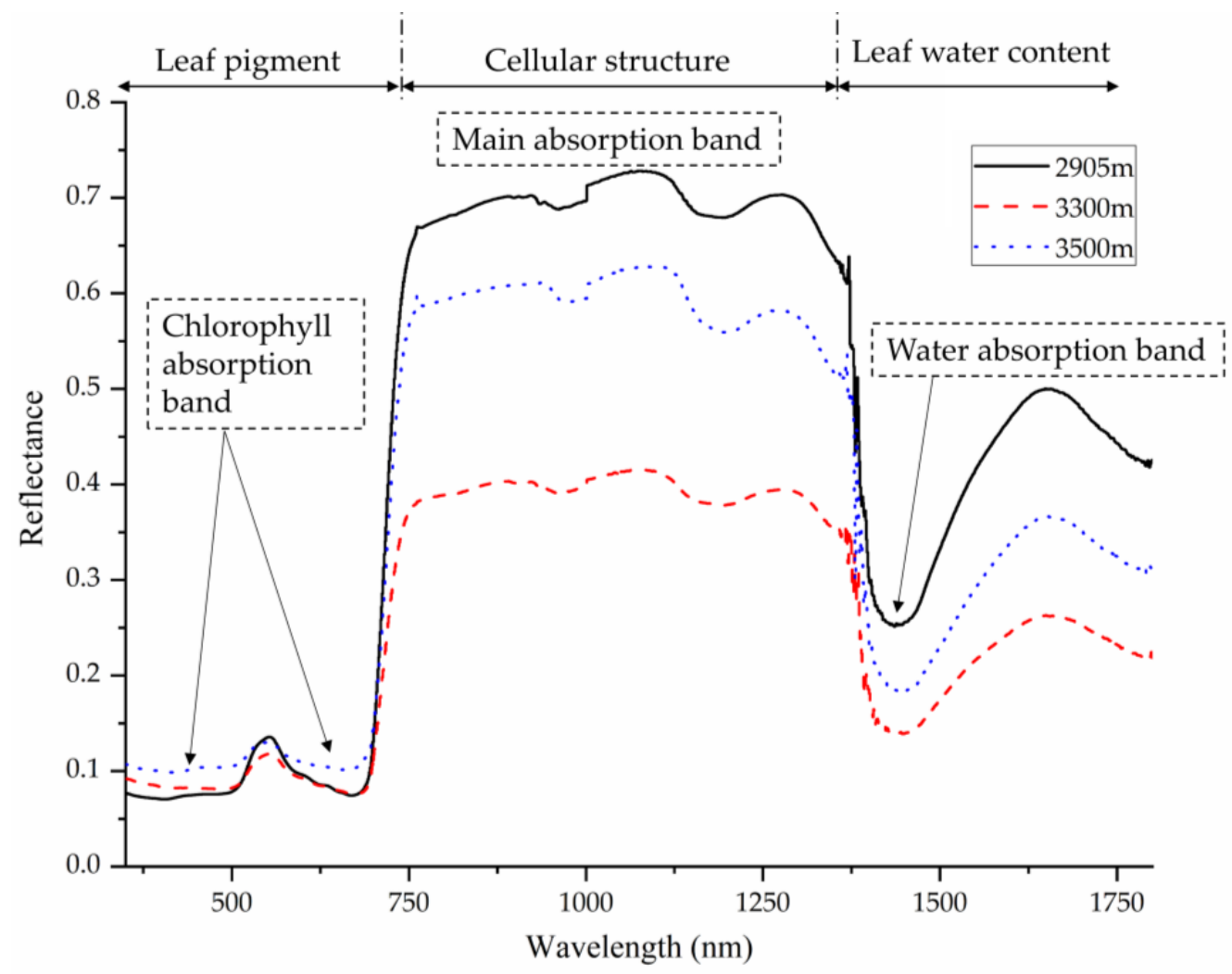

Figure 3. Reflectance spectral characteristics of Quercus aquifolioides leaves at different altitudes. 


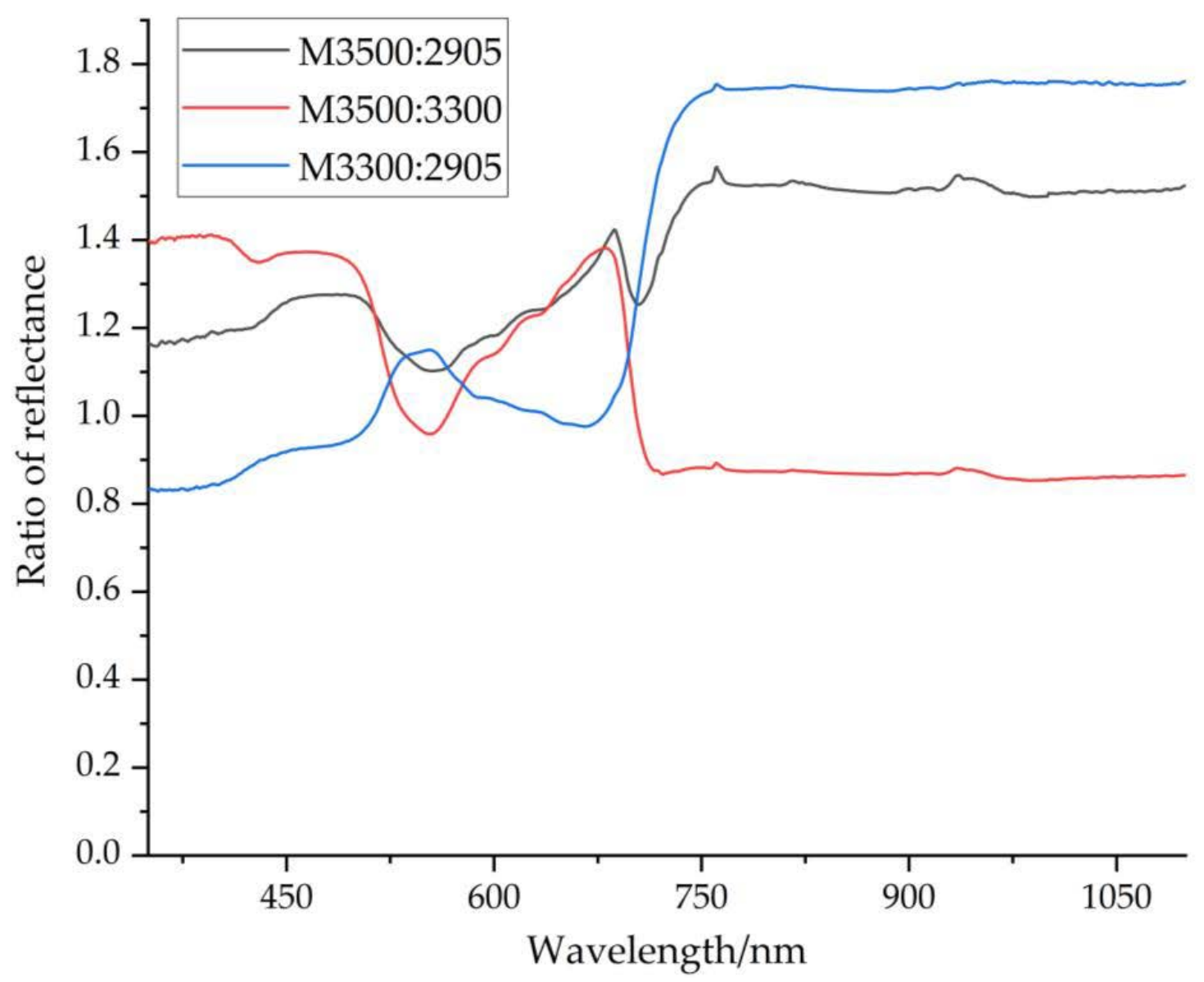

Figure 4. Spectral reflectance ratio of Quercus aquifolioides leaves at different altitudes.

\subsection{Dynamic Changes of Spectral Characteristic Parameters of Quercus aquifolioides at Different Altitudes}

Research shows that the original spectrum can eliminate the influence of background noise on the spectrum, and reduce the scattering and absorption of light by atmosphere in the process of spectrum acquisition, after first-order differential processing [35-37]. Representative hyperspectral characteristic parameters selected in this study were shown in Table 1 [38]. The "trilateration" parameter is an important in the first derivative spectrum, and is one of the hot spots and focuses in hyperspectral research in recent years. Among them, the red edge is the interval in which the reflection spectrum of plants suddenly changes obviously in the red light band $(680 \sim 750 \mathrm{~nm})$, which is the most significant mark in the spectrum curve, and is widely used as the characterization parameters of plant growth, leaf water content, nutritional status, chlorophyll content and other indicators [39]. Red edge includes two important concepts: the position of red edge and the other is the slope of red edge. The red edge position is the wavelength position corresponding to the maximum reflectance in the red wavelength band. It represents the degree of stress of plants to the external environment well [39-41]. For example, under the conditions of environmental pollution, disease threat, drought stress and so on, its position tends to shift to a certain extent. Generally speaking, there are two main directions for the shift of the red edge position, one is to shift towards the long wave direction, while the other is to shift towards the short wave direction. The red edge slope is the maximum reflectance in the red band, which can better reflect the chlorophyll content of plants and is often closely related to the photosynthetic rate of plants [42]. 
Table 1. Description of spectral parameters.

\begin{tabular}{cc}
\hline Spectral Parameters & Definition \\
\hline Red edge position, REP & The wavelength position corresponding to RES \\
Red edge slope, RES & The largest first-order derivative value in the red edge $(680 \sim 750 \mathrm{~nm})$ \\
Blue edge position, BEP & The wavelength position corresponding to BES \\
Blue edge slope, BES & The largest first-order derivative value in the blue edge $(490 \sim 530 \mathrm{~nm})$ \\
Yellow edge position, YEP & The wavelength position corresponding to YES \\
Yellow edge slope, YES & The largest first-order derivative value in the yellow edge (560 640 nm) \\
Red valley position, RVP & The wavelength position corresponding to RRV \\
Reflectance of red valley, RRV & Minimum reflectance in the wavelength range of $640 \sim 700 \mathrm{~nm}$ \\
Green peak position, GPP & The wavelength position corresponding to RGP \\
Reflectance of green peak, RGP & Maximum reflectance in the wavelength range of $510 \sim 580 \mathrm{~nm}$ \\
Reflectance of water stress band, RWSB & Maximum reflectivity in the wavelength range of 1550 1750 nm \\
Red edge area, REA & Sum of first derivative in red edge $(680 \sim 750 \mathrm{~nm})$ \\
Yellow edge area, YEA & Sum of first derivative in yellow edge $(490 \sim 530 \mathrm{~nm})$ \\
Blue edge area, BEA & Sum of first derivative in blue edge $(560 \sim 640 \mathrm{~nm})$ \\
Leaf chlorophyll index, LCI & $\left(R_{850}-R_{710}\right) /\left(R_{850}-R_{680}\right)$ \\
\hline
\end{tabular}

From Figures 5 and 6, it can be seen that the general trend of the first derivative spectra of Quercus aquifolioides leaves, at different altitudes, was basically the same, but there were some differences in values. As shown in Figure 6a, the red edge position and the red valley position of the leaf surface spectral curve move toward the short wave direction as the altitude increases. This showed that, with the increase in altitude, the effect on the position of red edge and red valley on leaf surface became more severe. However, the yellow edge position and the green peak position move to the long wave direction first and then to the short wave direction with the elevation. As shown in Figure $6 \mathrm{~b}$, with the elevation increasing, the water stress band reflectance and green peak reflectance first increased and then decreased, while the red valley reflectance increased. The slope of red edge, yellow edge and blue edge all decreased with the elevation. As can be seen from Figure 6c, with the elevation increasing, the red edge area first decreases and then increases, the yellow edge area decreases and the blue edge area increases. Previous studies generally believed that chlorophyll is one of the important parameters in determining the characteristics of plant spectral reflectance curves. When the vegetation is in a healthy growth state and has a high chlorophyll content, the red edge position generally moves towards the long wave direction. However, when vegetation is subjected to external environmental stress, such as drought stress, high temperature stress or pest damage, the red edge position tends to move towards short wave direction [41,42]. In this study, the red edge of Quercus aquifolioides showed a decreasing trend with the elevation. This just proves the indication effect of red edge position on chlorophyll content.

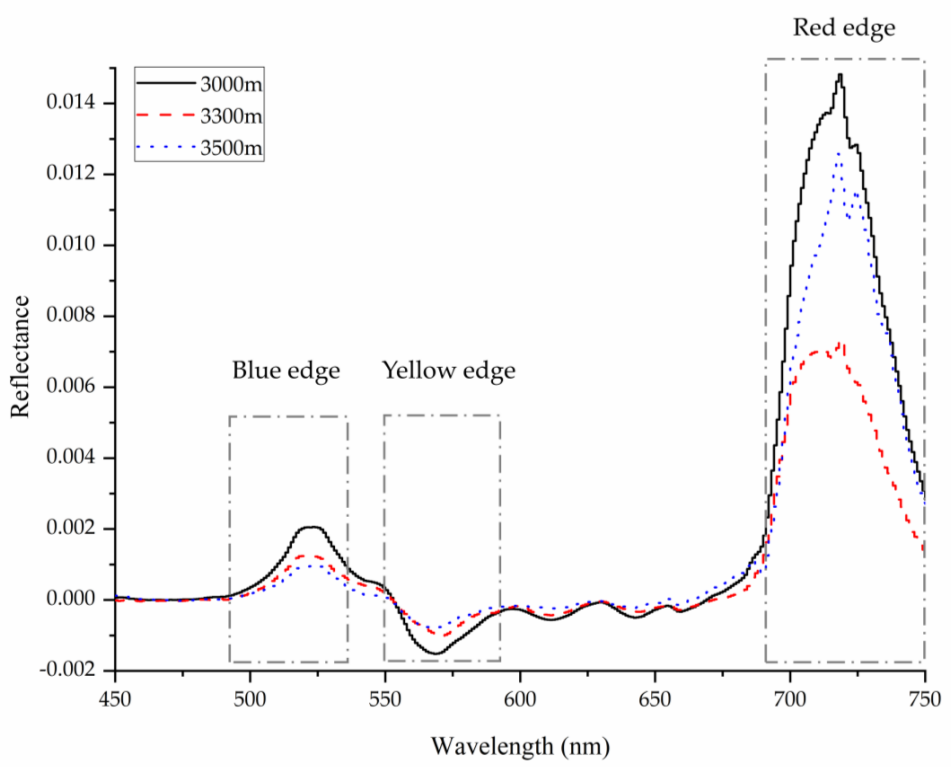

Figure 5. The first derivative spectral curves of the Quercus aquifolioides leaves at different altitudes. 


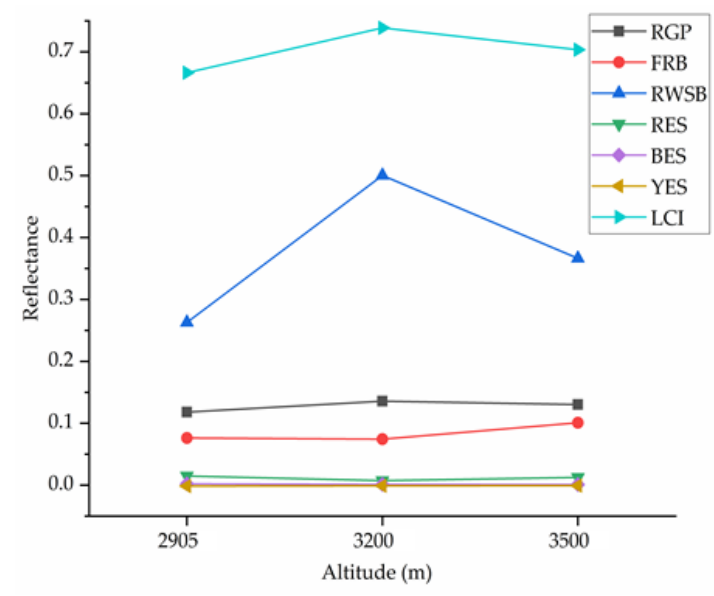

(a)

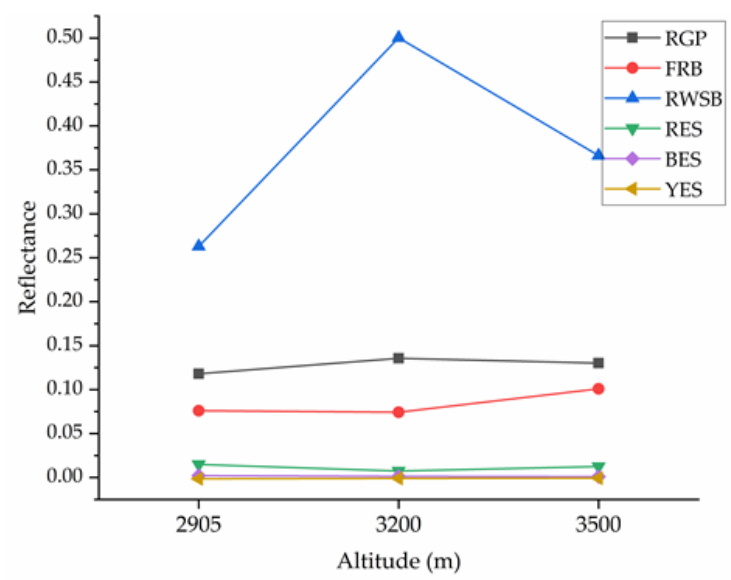

(b)

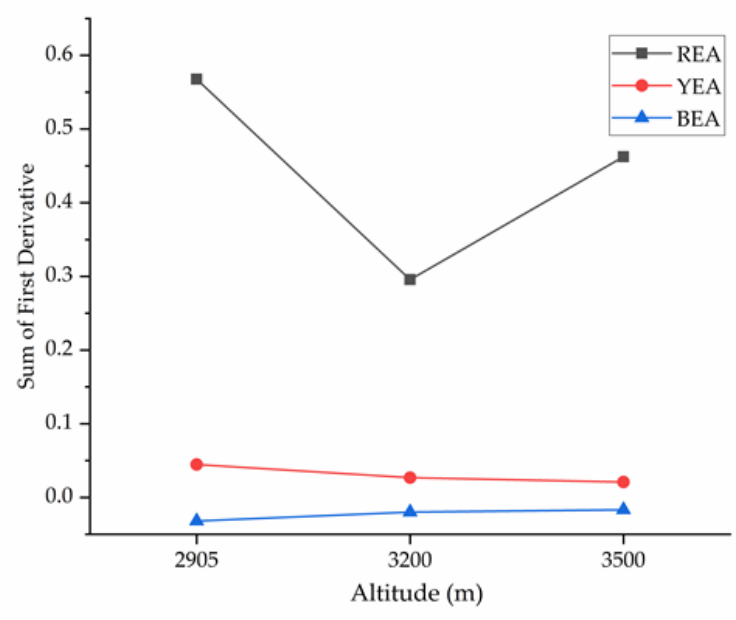

(c)

Figure 6. Spectral parameters of Quercus aquifolioides leaves at different altitudes. (a) spectral position, (b) spectral reflectance, (c) spectral area parameter. REP (red edge position), RES (red edge slope), BEP (blue edge position), BES (blue edge slope), YEP (yellow edge position), YES (yellow edge slope), RVP (red valley position), RRV (reflectance of red valley), GPP (green peak position), RGP (reflectance of green peak), RWSB (reflectance of water stress band), REA (red edge area), YEA (yellow edge area), BEA (blue edge area). 


\subsection{Correlation between Leaf Spectra and Derivative Spectra and Chlorophyll Content in Leaves}

As shown in Figure 7, the leaf reflectance spectral data, and its first derivative spectral data, were subjected to single correlation analysis with chlorophyll relative content values, respectively. The correlation coefficient between the original spectral reflectance and CCI value, the first derivative spectrum and CCI value on each spectral channel was calculated. The correlation curve between the original spectrum of Quercus aquifolioides leaves and the CCI value of the relative content of chlorophyll has the best correlation between the wavelength of 509 650 nm, and this wavelength was just the strong absorption band of chlorophyll. The correlation was almost zero at $761 \mathrm{~nm}$, i.e., the original spectrum hardly reflects chlorophyll content information after $761 \mathrm{~nm}$. The correlation between the first derivative spectrum and CCI value was the best and most stable at $450 \sim 500 \mathrm{~nm}$, and the correlation in other spectral channels fluctuates greatly.

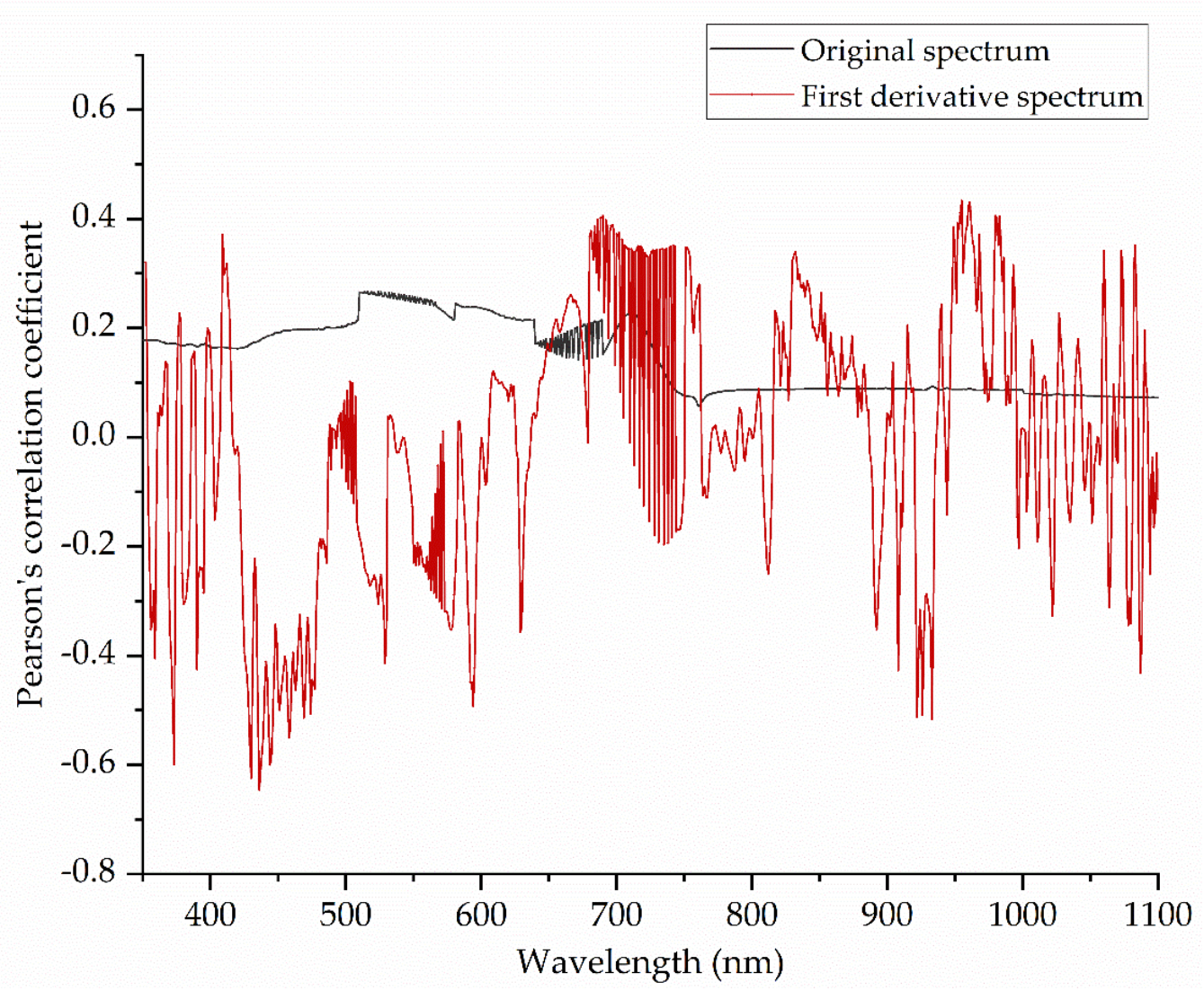

Figure 7. Correlation analysis and comparison of leaf spectrum, first derivative spectrum data and CCI value of relative chlorophyll content of Quercus aquifolioides.

\subsection{Correlation between Leaf Spectral Parameters and Chlorophyll Relative Values of Quercus aquifolioides at Different Altitudes}

Spectral parameters can better reflect the spectral characteristics of green vegetation, and they are sensitive to changes in chlorophyll content [43]. It is pointed out that there is an exponential function relationship between chlorophyll content and the reflectance spectral characteristic parameters such as red edge slope, blue edge slope and green peak reflectance [44-48]. Therefore, we used 13 typical spectral characteristic variables of plants and chlorophyll content of leaves for correlation analysis. Table 2 showed that there was a certain correlation between spectral parameters and relative chlorophyll content. Among them, the correlation between RES, BES, YES, YEP, RGP, RWSB, REA, BEA, YEA, LCI and chlorophyll relative content value has reached significant level. The correlation degree of green peak reflectance is the largest among all spectral parameters, which showed that RGP 
was the most sensitive to the relative chlorophyll content of Quercus aquifolioides. The change of this parameter can be used to characterize the change of chlorophyll content of Quercus aquifolioides at different altitudes.

Table 2. Relationships between chlorophyll content index and spectral feature parameters. * indicates that the correlation reaches a significant level at the level of $0.05, * *$ indicates that it is extremely significant at the level of 0.01 . The number of samples $n=60$.

\begin{tabular}{cc}
\hline Spectral Parameter & Correlation Coefficient \\
\hline REP & 0.162 \\
RES & $-0.292^{*}$ \\
BEP & -0.031 \\
BES & $-0.484^{* *}$ \\
YEP & -0.098 \\
YES & $-0.270^{*}$ \\
YEP & $-0.421^{*}$ \\
RGP & $-0.892^{* *}$ \\
GPP & -0.023 \\
RWSB & $-0.623^{* *}$ \\
REA & $-0.318^{*}$ \\
BEA & $0.461^{*}$ \\
YEA & $-0.264^{*}$ \\
LCI & $-0.335^{*}$ \\
\hline
\end{tabular}

\subsection{Estimation Model of Chlorophyll Content in Plant Leaves Based on Spectral Parameters}

From Table 2, it can be seen that the chlorophyll content of plant leaves has a good correlation with 10 spectral parameters (RES, BES, YES, YEP, RGP, RWSB, REA, BEA, YEA and LCI), which indicated that it was feasible to estimate the chlorophyll content of Quercus aquifolioides in Sejila Mountain by using these spectral characteristic variables. As shown in Table 3, this study takes 9 typical plant spectral characteristic parameters as independent variables and chlorophyll content as dependent variables, and conducts univariate regression analysis to establish an index, linear and quadratic polynomial chlorophyll content estimation model. Among them, the estimation model $R^{2}$ of RGP was the highest $\left(\mathrm{y}=206.98 \mathrm{e}^{-10.85 \mathrm{x}}, R^{2}=0.8523\right)$, which showed that this model has high accuracy (Figure 8). After the establishment of the estimation model, in order to verify the reliability and applicability of the estimation model, the estimation model was evaluated with three general indexes of root mean square error (RMSE), relative error (RE) and determination coefficient $\left(R^{2}\right)$ (Table 4 ), and the relationship diagram between the predicted value and the measured value was drawn (Figure 9) to visually show the fitting degree and reliability of the estimation model. The test results showed that the chlorophyll content estimation model based on the spectral characteristic parameters of RGP has achieved good test results. The determination coefficient $\left(R^{2}\right)$ of the test fitting equation reaches above 0.8 , and the root mean square error (RMSE) and relative error (RE) were both small, with higher fitting accuracy and smaller relative error. The estimation model of vegetation chlorophyll content has the largest determining coefficient $\left(R^{2}=0.8024\right)$, the smallest root mean square error (RMSE $=3.0512$ ), the smallest relative entropy $(\mathrm{MRE}=9.1721)$ and the smallest relative error $(\mathrm{RE}=6.13 \%)$, and the prediction accuracy reaches $95.85 \%$. 


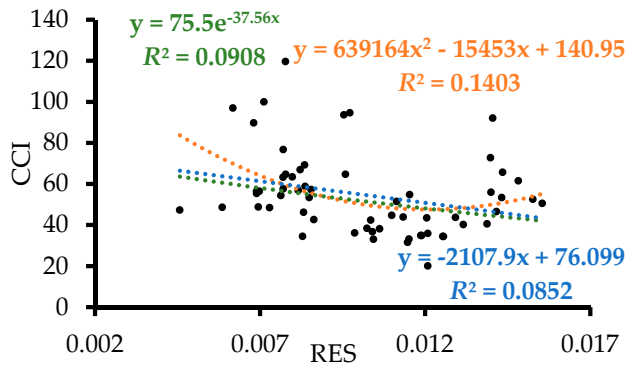

(a)

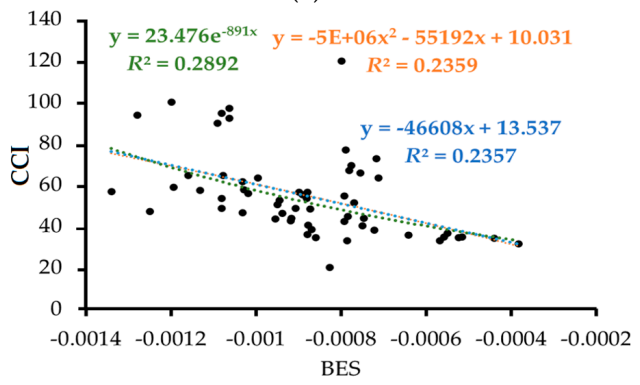

(c)

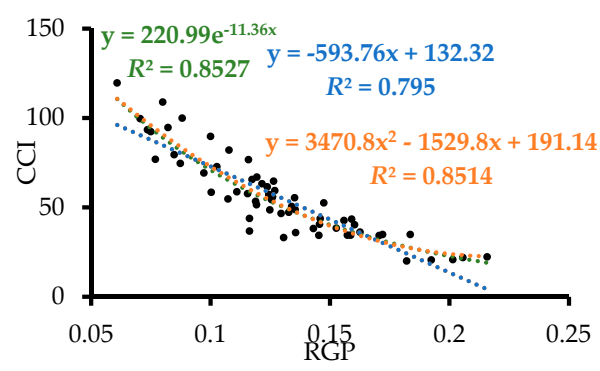

(e)

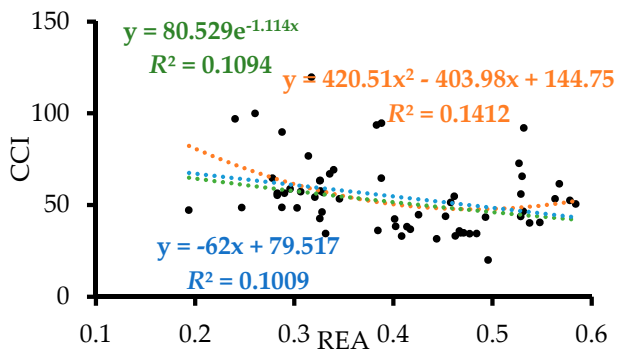

(g)

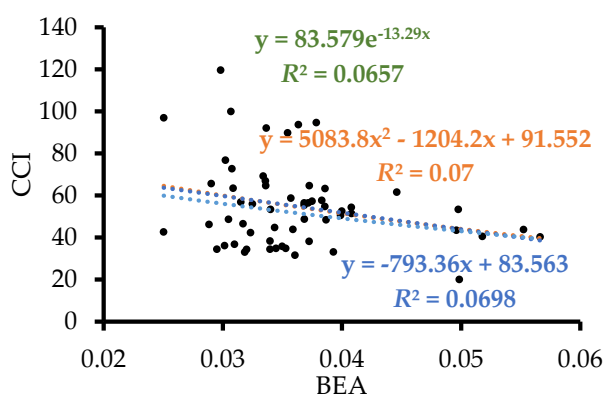

(i)

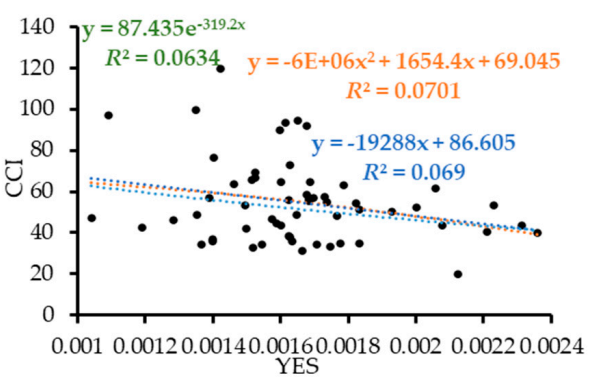

(b)

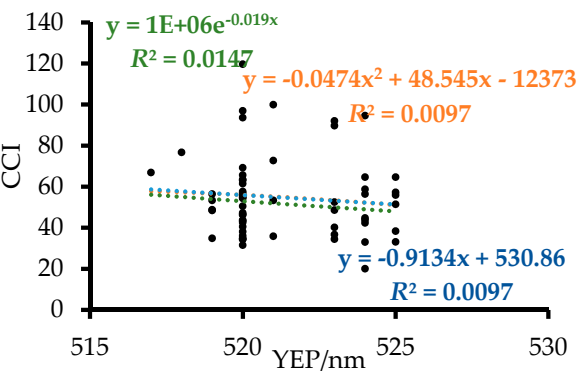

(d)

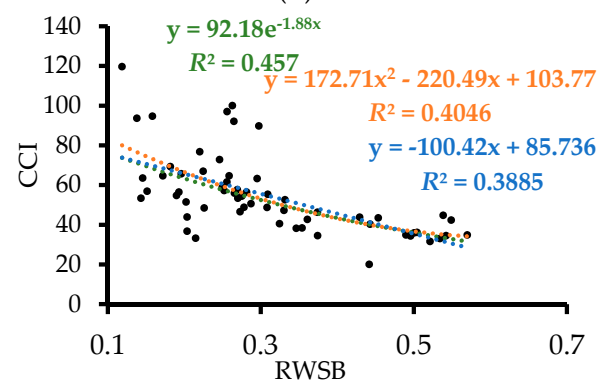

(f)

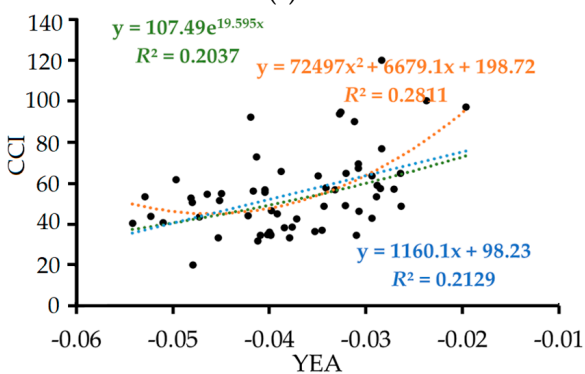

(h)

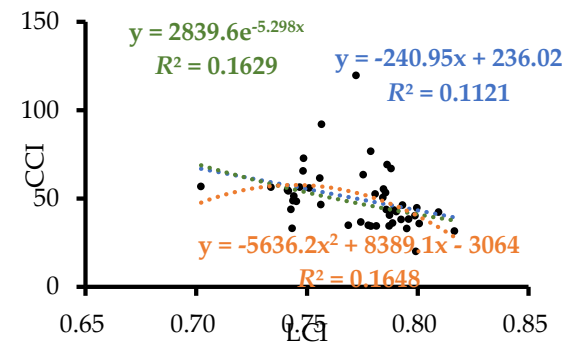

(j)

Figure 8. Regression model between chlorophyll content and best spectral parameter. (a) RES (red edge slope), (b) YES (yellow edge slope), (c) BES (blue edge slope), (d) YEP (yellow edge position), (e) RGP (reflectance of green peak), (f) RWSB (reflectance of water stress band), (g) REA (red edge area), (h) YEA (yellow edge area), (i) BEA (blue edge area), (j) LCI (leaf chlorophyll index). CCI (chlorophyll content index). 
Table 3. Regression model of chlorophyll content and spectral parameters (sample number $=60$ ).

\begin{tabular}{|c|c|c|}
\hline Spectral Parameter & Regression Model & Decisive Coefficient \\
\hline RES & $\begin{array}{c}y=75.5 e^{-37.56 x} \\
y=-2107.9 x+76.099 \\
y=639,164 x^{2}-15,453 x+140.95\end{array}$ & $\begin{array}{l}R^{2}=0.0908 \\
R^{2}=0.0852 \\
R^{2}=0.1403\end{array}$ \\
\hline BES & $\begin{array}{c}y=23.476 e^{-891 x} \\
y=-46,608 x+13.537 \\
y=-5 E+06 x^{2}-55,192 x+10.031\end{array}$ & $\begin{array}{l}R^{2}=0.2892 \\
R^{2}=0.2357 \\
R^{2}=0.2359\end{array}$ \\
\hline YES & $\begin{array}{c}y=87.435 e^{-319.2 x} \\
y=-19,288 x+86.605 \\
y=-6 E+06 x^{2}+1654.4 x+69.045\end{array}$ & $\begin{array}{l}R^{2}=0.0634 \\
R^{2}=0.0690 \\
R^{2}=0.0701\end{array}$ \\
\hline YEP & $\begin{array}{c}y=1 E+06 e^{-0.019 x} \\
y=-0.9134 x+530.86 \\
y=-0.0474 x^{2}+48.545 x-12,373\end{array}$ & $\begin{array}{l}R^{2}=0.0147 \\
R^{2}=0.0097 \\
R^{2}=0.0097\end{array}$ \\
\hline RGP & $\begin{array}{c}y=220.99 e^{-11.36 x} \\
y=-563.33 x+128.09 \\
y=3124.9 x^{2}-1411.9 x+181.94\end{array}$ & $\begin{array}{l}R^{2}=0.8523 \\
R^{2}=0.7368 \\
R^{2}=0.7840\end{array}$ \\
\hline RWSB & $\begin{array}{c}y=92.18 e^{-1.88 x} \\
y=-100.42 x+85.736 \\
y=172.71 x^{2}-220.49 x+103.77\end{array}$ & $\begin{array}{l}R^{2}=0.4570 \\
R^{2}=0.3885 \\
R^{2}=0.4046\end{array}$ \\
\hline REA & $\begin{array}{c}y=80.529 e^{-1.114 x} \\
y=-62 x+79.517 \\
y=420.51 x^{2}-403.98 x+144.75\end{array}$ & $\begin{array}{l}R^{2}=0.1094 \\
R^{2}=0.1009 \\
R^{2}=0.1412\end{array}$ \\
\hline YEA & $\begin{array}{c}y=107.49 e^{19.595 x} \\
y=1160.1 x+98.23 \\
y=72,497 x^{2}+6679.1 x+198.72\end{array}$ & $\begin{array}{l}R^{2}=0.2037 \\
R^{2}=0.2129 \\
R^{2}=0.2811\end{array}$ \\
\hline BEA & $\begin{array}{c}y=83.579 e^{-13.29 x} \\
y=-793.36 x+83.563 \\
y=5083.8 x^{2}-1204.2 x+91.552\end{array}$ & $\begin{array}{l}R^{2}=0.0657 \\
R^{2}=0.0698 \\
R^{2}=0.0700\end{array}$ \\
\hline LCI & $\begin{array}{c}y=2839.6 e^{-5.298 x} \\
y=-240.95 x+236.02 \\
y=-5636.2 x^{2}+8389.1 x-3064\end{array}$ & $\begin{array}{l}R^{2}=0.1629 \\
R^{2}=0.1121 \\
R^{2}=0.1648\end{array}$ \\
\hline
\end{tabular}

Table 4. The fit evaluation indicators of the measured values $(\mathrm{x})$ and predicted values (y).

\begin{tabular}{ccccc}
\hline Regression Equation & $\begin{array}{c}\boldsymbol{R}^{2} \text { (Determination } \\
\text { Coefficient) }\end{array}$ & $\begin{array}{c}\text { RMSE (Root Mean } \\
\text { Square Error) }\end{array}$ & $\begin{array}{c}\text { MRE\% (Min Relative } \\
\text { Entropy) }\end{array}$ & $\begin{array}{c}\text { RE\% } \\
\text { (Relative Error) }\end{array}$ \\
\hline $\mathrm{y}=0.7812 x+9.1464$ & 0.8024 & 3.0512 & 9.1721 & 6.13 \\
\hline
\end{tabular}

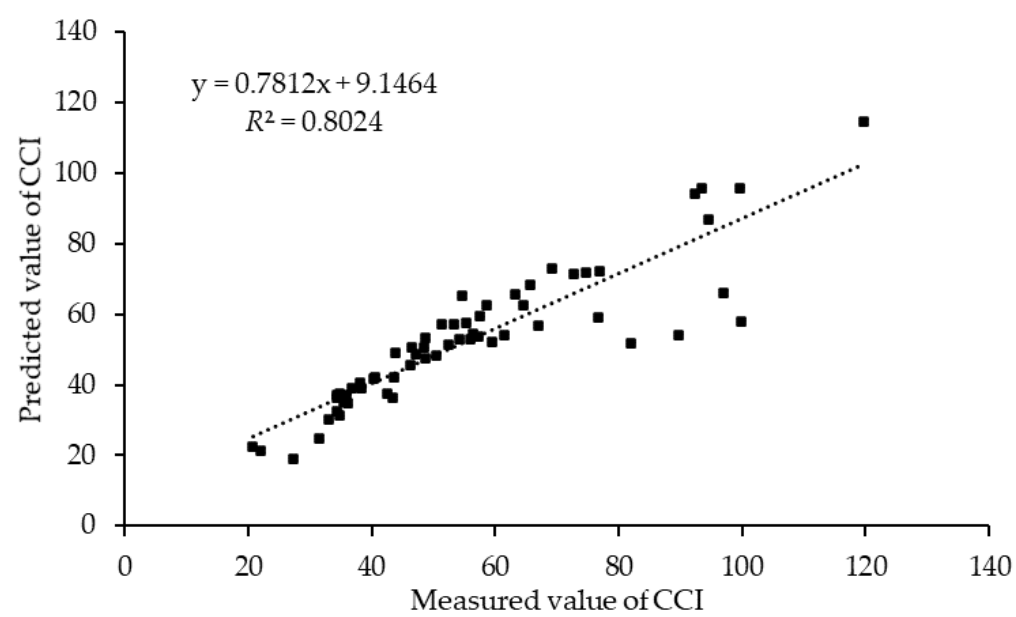

Figure 9. Comparison between the measured value and the predicted value (sample number $=60$ ). CCI (chlorophyll content index). 


\section{Conclusions and Discussion}

In this study, hyperspectral reflectance data of Quercus aquifolioides leaves measured by portable spectrometer and chlorophyll content measured synchronously were used. The spectral characteristics of Quercus aquifolioides leaves, at different altitudes, were analyzed, and the statistical analysis methods of correlation analysis and stepwise regression analysis were used. Through systematic analysis of the selected typical spectral characteristic parameters, the optimal spectral characteristic parameters for monitoring the chlorophyll content of Quercus aquifolioides were determined, and the estimation model of the chlorophyll content of Quercus aquifolioides was established. The estimation model was tested and verified by using $3 \mathrm{~K}-\mathrm{CV}$ method in cross-examination. The conclusion was as follows.

(1) The relative values of chlorophyll content of Quercus aquifolioides at different altitude gradients were significantly different. From $2905 \mathrm{~m}$ to $3500 \mathrm{~m}$, the relative chlorophyll content of Quercus aquifolioides showed a trend of increasing first and then decreasing, which indicated that the environment at lower altitude or higher altitude was not conducive to chlorophyll synthesis and accumulation. At a low altitude of $2905 \mathrm{~m}$, due to insufficient light and human destruction, its chlorophyll content was reduced. $3300 \mathrm{~m}$ above sea level was the most suitable growth area for Quercus aquifolioides. However, with the further increase in altitude $(3500 \mathrm{~m})$, due to the aggravation of unfavorable environment such as low temperature, thin atmosphere or strong ultraviolet radiation, the plant's resistance ability is limited, which also limits the growth and development of Quercus aquifolioides.

(2) The trend changes of leaf spectral reflectance curves of Quercus aquifolioides were generally consistent under different altitude gradients. In the visible light band $(350 \sim 550 \mathrm{~nm})$, the spectral reflectance was $3500 \mathrm{~m}>3300 \mathrm{~m}>2905 \mathrm{~m}$. In the range of $550 \sim 700 \mathrm{~nm}$, the reflectivity was $3500 \mathrm{~m}>2905 \mathrm{~m}>3300 \mathrm{~m}$. In the near infrared band $(750 \sim 1100 \mathrm{~nm})$, the reflectivity was $2905 \mathrm{~m}$ $>3500 \mathrm{~m}>3300 \mathrm{~m}$.

(3) In the range of $350 \sim 1800 \mathrm{~nm}$, there were 4 main reflection peaks and five main absorption valleys in the leaf surface spectral reflection curve of Quercus aquifolioides, and their positions were basically the same. Visible light band was difficult to reflect the damage of host plants, while near infrared band $(750 \sim 1400 \mathrm{~nm})$ has the greatest degree of spectral reflectance discrimination. This band was the sensitive range of leaf spectral response of Quercus aquifolioides. At the same time, such variation characteristics were universal under different altitude conditions.

(4) The red edge position and red valley position of leaf surface spectral curve move towards short wave direction with the elevation. This showed that, with the increase in altitude, the effect on the position of red edge and red valley on leaf surface becomes more severe. However, the yellow edge position and the green peak position move to the long wave direction first, and then to the short wave direction with the elevation. With the increase of altitude, the red edge area first decreases and then increases, the yellow edge area decreases and the blue edge area increases.

(5) The correlation curve between the original spectrum of Quercus aquifolioides leaves and chlorophyll relative content was the best between the wavelengths $509 \sim 650 \mathrm{~nm}$, and the original spectrum hardly reflects the chlorophyll content information after $761 \mathrm{~nm}$. The correlation between the first derivative spectrum and CCI value was the best and most stable at $450 \sim 500 \mathrm{~nm}$, and the correlation in other spectral channels fluctuates greatly.

(6) The correlation between red edge slope, blue edge slope, yellow edge slope, yellow edge position, green peak reflectance, water stress wave band reflectance, red edge area, yellow edge area and blue edge area and chlorophyll relative content value reached significant level. The correlation degree of green peak reflectance is the largest among all spectral parameters, which showed that green peak reflectance is most sensitive to the relative chlorophyll content of Quercus aquifolioides. The estimation model $R^{2}$ of green peak reflectivity was the highest $\left(\mathrm{y}=206.98 \mathrm{e}^{-10.85 \mathrm{x}}, R^{2}=0.8523\right)$, and the prediction accuracy was $95.85 \%$. 
Author Contributions: J.Z. conceived and designed the study. J.Z., Q.Y., W.H., C.X., and H.H. contributed materials and tools. J.Z., W.H., C.M.B.J. and J.Y. performed the experiments. J.Z. contributed to data analysis, paper preparation and revision. All authors have read and agreed to the published version of the manuscript.

Funding: This research is supported by the "Special fund project for basic scientific research business fees of the Central University of Beijing Forestry University: Study on Ecological Network Structure and Its Crash Threshold in the Northeastern Edge of Wulanbu Desert (BLX201806)" and the "China Postdoctoral Science Foundation Grant: Study on Structural Characteristics and Crash Threshold of Complex Ecological Network in Desert Oasis Ecotone (2018 M641218)".

Acknowledgments: The English in this document has been checked by at least two professional editors; both were native speakers of English.

Conflicts of Interest: The authors declare no conflict of interest. The founding sponsors had no role in the design of the study; in the collection, analyses, or interpretation of data; in the writing of the manuscript, and in the decision to publish the results.

\section{References}

1. Permana, H.H.; Widyastuti, Y.; Samanhudi, Y.A. Response of Artemisia annua L. to shade and manure fertilizer application in lowland altitude. Iop Conf. Ser. Earth Environ. Ence 2018, 142, 12-43.

2. Ghafari, S.; Ghorbani, A.; Moameri, M.; Mostafazadeh, R.; Bidarlord, M. Composition and structure of species along altitude gradient in moghan-sabalan rangelands, iran. J. Mt. Sci. 2018, 15, 1209-1228. [CrossRef]

3. Meinzer, F.C.; Rundel, G.H.G.W. Morphological changes along an altitude gradient and their consequences for an Andean Giant Rosette plant. Oecologia 1985, 65, 278-283. [CrossRef] [PubMed]

4. Yin, C.; Duan, B.; Wang, X.; Li, C. Morphological and physiological responses of two contrasting poplar species to drought stress and exogenous abscisic acid application. Plant Sci. 2004, 167, 1091-1097. [CrossRef]

5. Wang, J.R.; Hawkins, C.D.; Letchford, T. Relative growth rate and biomass allocation of paper birch (Betula papyrifera) populations under different soil moisture and nutrient regimes. Can. J. For. Res. 2011, $28,44-55$. [CrossRef]

6. Takahashi, K. Effects of altitude and competition on growth and mortality of the coniferAbies sachalinensis. Ecol. Res. 2010, 25, 801-812. [CrossRef]

7. Nikki, I.; Ushiyama, M.; Morita, I. Effects of the Altitude on the Growth and the Chemical Composition of Some Forage Crops. Jpn. J. Crop Sci. 1960, 28, 309-310. [CrossRef]

8. Wildi, B.; Lütz, C. Antioxidant composition of selected high alpine plant species from different altitudes. Plant Cell Environ. 1996, 19, 138-146. [CrossRef]

9. Buchner, O.; Neuner, G. Variability of Heat Tolerance in Alpine Plant Species Measured at Different Altitudes. Arct. Antarct. Alp. Res. 2003, 35, 411-420. [CrossRef]

10. Wang, Z.; Liu, H.; Wei, N.; Xu, W.; Liu, S. Effects of stand regeneration management regimes and age on genetic structure of Quercus aquifolioides (Sclerophyllous Oak) in southwestern china. For. Sci. 2009, 55, 142-148.

11. Zhang, X.J.; Korpelainen, H.; Li, C.Y. Microsatellite Variation of Quercus aquifolioides Populations at Varying Altitudes in the Wolong Natural Reserve of China. Silva Fenn. 2006, 40, 407-415. [CrossRef]

12. Panaiotis, C.; Carcaillet, C.; M'Hamedi, M. Determination of the natural mortality age of an holm oak (Quercus ilex L.) stand in Corsica (Mediterranean Island). Acta Oecologica 1997, 18, 519-530. [CrossRef]

13. Panaiotis, C.; Loisel, R.; Roux, M. Analysis of vegetation response to naturally occurring gaps in old-growth forests of Quercus ilex L. in Corsica. Can. J. For. Res. 1998, 28, 1125-1134.

14. Wang, X.F.; Lesi, M.C.; Zhang, M.M. Ecosystem pattern change and its influencing factors of "two barriers and three belts". Chin. J. Ecol. 2019, 38, 2138-2148.

15. Plieninger, T.; Pulido, F.J.; Schaich, H. Effects of land-use and landscape structure on holm oak recruitment and regeneration at farm level in Quercus ilex L. dehesas. J. Arid Environ. 2004, 57, 345-364. [CrossRef]

16. Zhu, J.; Yu, Q.; Zhu, H.; He, W.; Xu, C.; Liao, J.; Zhu, Q.; Su, K. Response of dust particle pollution and construction of a leaf dust deposition prediction model based on leaf reflection spectrum characteristics. Environ. Sci. Pollut. 2019. [CrossRef]

17. Liang, L.; Yang, M.; Zhang, L.; Lin, H.; Zhou, X. Chlorophyll content inversion with hyperspectral technology for wheat canopy based on support vector regression algorithm. Trans. Chin. Soc. Agric. Eng. 2012, 28, $162-171$. 
18. Li, J.B.; Wang, F.J.; Ying, Y.B.; Rao, X.Q. Application of hyperspectral fluorescence image technology in detection of early rotten oranges. Spectrosc. Spectr. Anal. 2012, 32, 142-146.

19. Zhu, J.; Yu, Q.; Liu, X.; Yu, Y.; Yao, J.; Su, K.; Niu, T.; Zhu, H.; Zhu, Q. Effect of leaf dust retention on spectral characteristics of Euonymus japonicus and its dust retention prediction. Spectrosc. Spectr. Anal. 2020, 40, 517-522.

20. Gamon, J.A.; Surfus, J.S. Assessing leaf pigment content and activity with a reflectometer. New Phytol. 1999, 143, 105-117. [CrossRef]

21. Richardson, A.D.; Berlyn, G.P. Spectral reflectance and photosynthetic properties of Betula papyrifera (Betulaceae) leaves along an elevational gradient on Mt. Mansfield, Vermont, USA. Am. J. Bot. 2002, 89, 88-94. [CrossRef] [PubMed]

22. Madeira, A.C.; Mentions, A.; Ferreira, M.E.; De Lourdes Taborda, M. Relationship between spectroradiometric and chloropuyll measurements in green beans. Commun. Soil Sci. Plant Anal. 2000, 31, 631-643. [CrossRef]

23. Poulos, H.M.; Goodale, U.M.; Berlyn, G.P. Drought response of two Mexican oak species, Quercus laceyi and Quercus sideroxyla (Fagaceae), in relation to elevational position. Am. J. Bot. 2007, 94, 809-818. [CrossRef] [PubMed]

24. Jiang, Y.W.; Duncan, R.R.; Carrow, R.N. Assessment of low light tolerance of seashore paspalum and bermudagrass. Crop Sci. Soc. Am. 2004, 44, 587-594. [CrossRef]

25. Stylinski, C.D.; Gamon, J.A.; Oechel, W.C. Seasonal patterns of reflectance indices, catotemoid pigments and photosynthesis of evergreen chaparral species. Ecophysiology 2002, 131, 366-374.

26. Pietrzykowski, E.; Stone, C.; Pinkard, E.; Mohammed, C. Effects of My cosphaerella leaf disease on the spectral reflectance properties of juvenile Eucalyptus globulus foliage. For. Pathol. 2006, 36, 334-348. [CrossRef]

27. Fuentes, D.A.; Gamon, J.A.; Cheng, Y.F.; Claudio, H.C.; Qiu, H.L.; Mao, Z.Y.; Sims, D.A.; Rahman, A.F.; Oechel, W.; Luo, H.Y. Mapping carbon and water vapor fluxes in a chaparral ecosystem using vegetation indices derived from AVIRIS. Remote Sens. Environ. 2006, 103, 312-323. [CrossRef]

28. Garty, J.; Kloog, N.; Wolfson, R.; Cohen, Y.; Karnieli, A.; Avni, A. The influence of air pollution on the concentration of mineral elements, on the spectral reflectance response and on the production of stress-ethylene in the lichen Ramalina duriaei. New Phytol. 1997, 137, 587-597. [CrossRef]

29. Richardson, A.D.; Berlyn, G.P.; Gregoire, T.G. Spectral reflectance of Picea rubens (Pinaceae) and Abies balsamea (Pinaceae) needles along an elevational gradient, Mt. Moosilauke, New Hampshire, USA. Am. J. Bot. 2001, 88, 667-676. [CrossRef]

30. Richardson, A.D.; Duigan, S.P.; Berlyn, G.P. An evaluation of noninvasive methods to estimate foliar chlorophyll content. New Phytol. 2002, 153, 185-194. [CrossRef]

31. Pike, C.S.; Norman, H.A.; Kemmerer, E.C.; Wessner, D.R.; Ellis, A.A. Effects of acclimation to low temperature and to water stress on photosynthesis and on physical and chemical properties of lipids from thylakoids of cucumber and cotton. Plant Sci. 1990, 68, 189-196. [CrossRef]

32. Kofidis, G.; Bosabalidis, A.M.; Moustakas, M. Combined effects of altitude and season on leaf characteristics of Clinopodium vulgare L. (Labiatae). Environ. Exp. Bot. 2007, 60, 69-76. [CrossRef]

33. Wu, C.Y.; Wang, X.F. Research of foliar dust content estimation by reflectance spectroscopy of Euonymus japonicus Thunb. Environ. Nanotechnol. Monit. Manag. 2016, 5, 54-61. [CrossRef]

34. Yan, X.; Shi, W.Z.; Zhao, W.J.; Luo, N. Mapping dust-fall distribution in urban areas using remote sensing and ground spectral data. Sci. Total Environ. 2015, 506, 604-612. [CrossRef]

35. Manzo, C.; Salvini, R.; Guastaldi, E.; Nicolardi, V.; Protano, G. Reflectance spectral analyses for the assessment of environmental pollution in the geothermal site of mt. amiata (Italy). Atmos. Environ. 2013, 79, 650-665. [CrossRef]

36. Sridhar, B.B.M.; Han, F.X.; Diehl, S.V.; Monts, D.L.; Su, Y. Spectral reflectance and leaf internal structure changes of barley plants due to phytoextraction of zinc and cadmium. Int. J. Remote Sens. 2007, 28, 1041-1054. [CrossRef]

37. Mahlein, A.K.; Steiner, U.; Christian, H.; Dehne, H.W.; Oerke, E.C. Hyperspectral imaging for small-scale analysis of symptoms caused by different sugar beet diseases. Plant Methods 2012, 8, 3. [CrossRef]

38. Gong, Z.N.; Zhao, Y.L.; Zhao, W.J.; Lin, C.; Cui, T.X. Estimation model for plant leaf chlorophyll content based on the spectral index content. Acta Ecol. Sin. 2014, 34, 5736-5745. 
39. Daniel, A.S.; Gamon, J.A. Estimation of vegetation water content and photosynthetic tissue area from spectral reflectance: A comparison of indices based on liquid water and chlorophyll absorption features. Remote Sens. Environ. 2003, 84, 526-537.

40. Zarco-Tejada, P.J.; Rueda, C.A.; Ustin, S.L. Water content estimation in vegetation with MODIS reflectance data and model inversion methods. Remote Sens. Environ. 2003, 85, 109-124. [CrossRef]

41. Singh, S.K.; Hoyos-Villegas, V.; Ray, J.D.; Smith, J.R.; Fritschi, F.B. Quantification of leaf pigments in soybean (Glycine $\max$ (L.) merr.) based on wavelet decomposition of hyperspectral features. Field Crop. Res. 2013, 149, 20-32. [CrossRef]

42. Verrelst, J.; Schaepman, M.E.; Malenovs'y, Z.; Clevers, J.G.P.W. Effects of woody elements on simulated canopy reflectance: Implications for forest chlorophyll content retrieval. Remote Sens. Environ. 2010, 114, 647-656. [CrossRef]

43. Wu, D.; Huang, L.X.; He, Y.; Pan, J.Z.; Zhang, B. Visible- near infrared reflection spectroscopy for crop- weed discrimination. Acta Opt. Sin. 2008, 28, 1618-1622.

44. Song, K.S.; Zhang, B.; Wang, Z.M.; Liu, H.J.; Duan, H.T. Inverse model for estimating soybean chlorophyll concentration using in-situ collected canopy hyperspectral data. Trans. Chin. Soc. Agric. Eng. 2006, 22, 16-21.

45. Yi, Q.X.; Huang, J.F.; Wang, X.Z.; Qian, L. Hyperspectral remote sensing estimation models for chlorophyll concentration in corn. Bull. Sci. Technol. 2007, 23, 83-87.

46. Tang, Y.L.; Wang, R.C.; Huang, J.F.; Kong, W.S.; Cheng, Q. Hyperspectral data and their relationships correlativee to the pigment contents for rice under different nitrogen support level. J. Remote Sens. 2004, 8, 185-192.

47. Yang, J.; Tian, Y.C.; Yao, X.; Cao, W.X.; Zhang, Y.S.; Zhu, Y. Hyperspectral estimation model for chlorophyll concentrations in top leaves of rice. Acta Ecol. Sin. 2009, 29, 6561-6571.

48. Kakani, V.; Reddy, K.; Zhao, D.; Gao, W. Senescence and hyperspectral reflectance of cotton leaves exposed to ultraviolet-b radiation and carbon dioxide. Physiol. Plantarum 2004, 121, 250-257. [CrossRef]

(C) 2020 by the authors. Licensee MDPI, Basel, Switzerland. This article is an open access article distributed under the terms and conditions of the Creative Commons Attribution (CC BY) license (http://creativecommons.org/licenses/by/4.0/). 